\title{
Assessment of urban landscapes management
}

\author{
M. A. Martínez Gimeno ${ }^{1}$, J. Manzano ${ }^{2}$, I. Balbastre Peralta ${ }^{2}$ \\ \& J. García-Serra ${ }^{3}$ \\ ${ }^{1}$ Instituto Ingeniería del Agua y Medio Ambiente, \\ Universitat Politècnica de València, Spain \\ ${ }^{2}$ Departamento de Ingeniería Rural y Agroalimentaria, \\ Universitat Politècnica de València, Spain \\ ${ }^{3}$ Instituto Tecnológico del Agua, \\ Universitat Politècnica de València, Spain
}

\begin{abstract}
The paper is focused on making an integrated evaluation of hydraulic and energetic management in urban landscapes with the intention of detecting consumptions which are far from those recommended as best. The method is based on indentifying hydrozones inside plots and calculating their water needs. Additionally, an assessment methodology based on catch-can testing and quality irrigation indicators are proposed to appraise irrigation efficiency and uniformity. Finally, some energetic performance indicators for evaluating irrigation supply systems are defined. The protocol has been conducted in the gardens of the Universitat Politècnica de València (Spain) and a potential saving of $43 \%$ in water consumption could be achieved. Quality irrigation and energy performance was assessed and showed that the system is not operated under the optimum conditions. Keywords: urban landscapes, irrigation efficiency, assessment, inventory, uniformity, water needs.
\end{abstract}

\section{Introduction}

Southern Europe ecosystems have high water requirements, which are not compensated by the scarce rainfall typical in a semiarid country like Spain. The irrigation needs in urban landscapes can reach a volume around a $9 \%$ of the total amount of water resources used in urban areas (INE [1]). Besides, most irrigation systems require energy to operate because they do not have enough elevation for 
supplying water by gravity. This leads to an important energy consumption ranging between 0.95 and $1.18 \mathrm{kWh} / \mathrm{m}^{3}$ (Soto-García et al. [2]), with the environmental and economic impact that this involves. The main purpose in management tasks should be to save water because this aim will mean saving energy.

Management and maintenance of green areas is not always the desired. At the project level or in the early stages of garden management, facilities are built according to the theoretical conditions but with time, deficiencies and changes in vegetal species often arise and it is essential to detect and to correct them for achieving irrigation efficiency. The study is centered on assessing management of hydraulic and energetic resources in an integrated way with the intention of detecting consumptions which are far from those recommended as best. Besides, resource consumptions and irrigation uniformity are strongly linked by means of the relation flow-pressure and the emitter coefficients that determine emitters' performance. If there are any discrepancy in these parameters, quality irrigation and water and energy consumptions will be altered.

\section{Materials and methods}

\subsection{Pilot site}

The methodology developed in this document was conducted in the gardens of the Universitat Politècnica de València (UPV), Spain $\left(39^{\circ} 28^{\prime} 54^{\prime}\right.$ ' $\mathrm{N}, 0^{\circ} 20^{\prime} 37^{\prime}$ ' $\mathrm{W}$, $7 \mathrm{~m}$ about sea level). The campus has $106,000 \mathrm{~m}^{2}$ of landscaped area with more than 2300 trees. The garden has an irrigation system divided in two networks operated by two pumping units. The study is concentrated on the subnet called well two (w2) where there are 160 intakes and approximately 1400 emitters (sprinklers and diffusers). The irrigation network is operated by a centralized remote system that enables to establish irrigation scheduling by means of opening or shutting electrovalves than run groups of emitters.

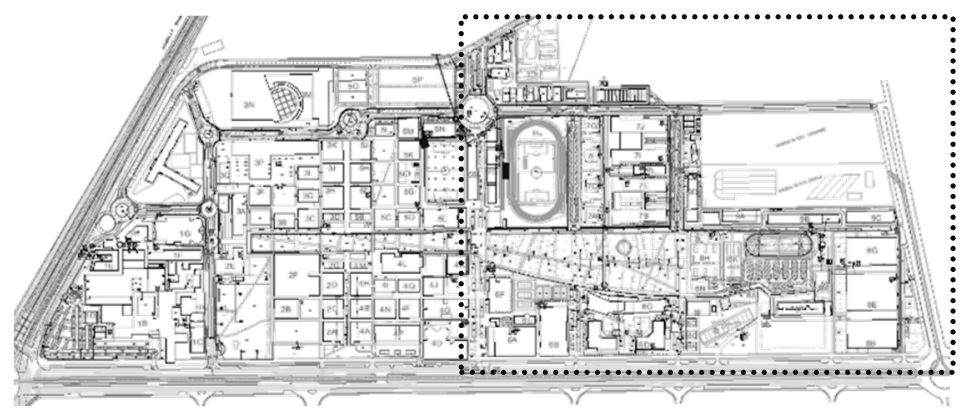

Figure 1: Pilot site. Subarea w2 highlighted.

\subsection{Water needs for urban landscapes}

The first step aims at saving resources is to calculate the precise water amount required by plants. Water saving is essential so the calculation has been formulated 
taking into account two important concepts: xeriscape and deficit irrigation (Burés [3]). Both of them are terms which promote an efficient irrigation under optimum water requirements.

The methodology chosen to calculate irrigation scheduling was the landscape coefficient method (Costello et al. [4]). It basically consists of obtaining landscape evapotranspiration (ET) by multiplying a landscape coefficient $\left(\mathrm{K}_{\mathrm{j}}\right)$ and the reference evapotranspiration $\left(\mathrm{ET}_{\mathrm{o}}\right)$ :

$$
E T=E T_{o} \times K_{j}
$$

where $\mathrm{ET}_{\mathrm{o}}$ was calculated using Allen et al. [5] recommendations. Despite, this approach is the most frequent; there are several options for estimating $\mathrm{ET}_{0}$ like models used by Van Damm et al. [6] or Qualls et al. [7], among others.

Landscape coefficient is calculated from three factors: species $\left(\mathrm{K}_{\mathrm{e}}\right)$, microclimate $\left(\mathrm{K}_{\mathrm{mc}}\right)$ and density $\left(\mathrm{K}_{\mathrm{d}}\right)$. These factors are used in the landscape coefficient formula as follows:

$$
K_{j}=K_{e} \times K_{m c} \times K_{d}
$$

In this work, for estimating landscape factors, it is recommended to use the guidebook called WUCOLS (acronym for Water Use Classifications of Landscape Species) developed by Costello et al. [4] and the reference document (Contreras [8]), for Mediterranean conditions. These coefficients are detailed in the Table 1 and they have been selected considering that vegetal species are adapted to semiarid conditions. Finally, water needs of landscape plantings $\left(\mathrm{NR}_{\mathrm{r}}\right)$ can be estimated using following equations:

$$
\begin{gathered}
P_{e f}=0.75(P-5) \\
F L=\frac{E C_{w}}{5 x E C_{e}-E C_{w}} \times \frac{1}{L_{e}} \\
N R_{r}=\frac{N R_{n}}{E_{a} \times(1-F L)} \text { where } N R_{n}=E T-P_{e f}
\end{gathered}
$$

where $P_{\text {ef }}$ is the effective rainfall $(\mathrm{mm} /$ day), $P$ is the rainfall $(\mathrm{mm} /$ day), $\mathrm{FL}$ is the leaching fraction (-), $\mathrm{EC}_{\mathrm{w}}$ is the irrigation water electrical conductivity $(\mathrm{dS} / \mathrm{m})$, $\mathrm{EC}_{\mathrm{e}}$ is the saturation extract electrical conductivity $(\mathrm{dS} / \mathrm{m}), \mathrm{L}_{\mathrm{e}}$ is the lixiviation efficiency (0.7), $\mathrm{NR}_{\mathrm{n}}$ is the net water requirement ( $\mathrm{mm} /$ day), ET is the landscape evapotranspiration $\left(\mathrm{mm} /\right.$ day) and $E_{a}$ is the irrigation system efficiency that is 0.8 for sprinklers and diffusers, and 0.9 for drippers. These factors have been defined for six hydrozones that simplified reflect usual conditions of urban landscapes. Coefficients are shown in the Table 1.

\subsection{Uniformity irrigation measurements}

The protocol assessment proposed is focused on reducing water and energy consumption. In the case of urban landscapes, it should be achieved by maximizing irrigation efficiency. This attribute can be computed as the ratio between the water used beneficially by plants and water applied in plots (Burt et $a l$. [9]). This is a complex parameter to quantify; therefore, it can be obtained by 
Table 1: Coefficients to estimate water needs.

\begin{tabular}{|c|l|c|c|c|c|}
\hline \multicolumn{2}{|c|}{ Hydrozones } & $\mathrm{K}_{\mathrm{e}}$ & $\mathrm{K}_{\mathrm{d}}$ & $\mathrm{K}_{\mathrm{mc}}$ & $\mathrm{E}_{\mathrm{a}}$ \\
\hline 1 & Xerophytic plants + Drippers + Not shading & 0.1 & 0.8 & 1.0 & 0.9 \\
\hline 2 & Intensive turf + Sprinklers + Not shading & 0.6 & 0.8 & 1.0 & 0.8 \\
\hline 3 & Turf + Sprinklers + Not shading & 0.4 & 0.8 & 1.0 & 0.8 \\
\hline 4 & Xerophytic plants + Drippers + Shading & 0.1 & 0.8 & 0.6 & 0.9 \\
\hline 5 & Intensive turf + Sprinklers + Shading & 0.6 & 0.8 & 0.6 & 0.8 \\
\hline 6 & Turf + Sprinklers + Shading & 0.4 & 0.8 & 0.6 & 0.8 \\
\hline
\end{tabular}

means of distribution uniformity. To quantify quality irrigation the catch-can method of uniformity testing was used. This assessment method is described by both the National Resources Conservation Service (NRCS) and the American Society for Agricultural Engineers (ASAE) (Micker [10] and ASAE [11]). The catch-cans were distributed on the turf area and around the plot to measure water losses in a square grid where approximately four cans were between sprinklers. In the UPV plots this distance was $2.5 \mathrm{~m}$. The irrigation system was set to run for 20 minutes that is the usual irrigation time in the UPV, and then catch-can volumes were measured immediately following the test using an electronic scale. Water weighs were transformed to water depths and rainfall, and were represented spatially using an interpolation tool (IDW) from ArcGIS 10.1 [12].

The most of the irrigation schedules are determined for areas that receive less water in the plot. However, if it is applied excess water in order to there is enough water in dry areas, deep percolation and plant oxygen stress can occur. The goal of this second part of the assessment is to determine some indicator that detects these irrigation deficiencies from previous catch-can measurements.

\subsubsection{Uniformity indicators}

Uniformity of water distribution is a measure of the variability in application depth over a given area. Tree indicators have been used to quantify uniformity.

Coefficient of uniformity (CU): This indicator defined by Christiansen [13] has the strongest historical precedent in the sprinkler irrigation industry. It is defined as:

$$
C U(\%)=100 x\left(1-\frac{\sum_{i=1}^{n}\left|x_{i}-x_{m}\right|}{n x_{m}}\right)
$$

where $x_{i}$ is the measured depth of water in equally spaced catch-cans on a grid $(\mathrm{mm}), \mathrm{x}_{\mathrm{m}}$ is the mean depth of water in all the catch-cans $(\mathrm{mm})$ and $\mathrm{n}$ is the number of catch-cans used (-).

Distribution uniformity (DU): The uniformity for surface irrigation systems is commonly characterized by this indicator (Merriam and Keller [14]), defined as:

$$
D U(\%)=100 x\left(\frac{x_{l q}}{x_{m}}\right)
$$


where $\mathrm{x}_{\mathrm{lq}}$ is the average depth measured in the low one-quarter on the catch-cans method (mm).

Scheduling coefficient (SC): This indicator is used to estimate how long the irrigation system must operate to wet the dry spots. It is defined as:

$$
S C=\frac{x_{m}}{x_{a e}}
$$

where $\mathrm{X}_{\mathrm{ae}}$ is the depth of water in the driest continuous application area (mm).

\subsubsection{Efficiency indicators}

Apart from knowing water distribution in the plot, it is essential to assess which portion of irrigation is actually usable by the plants. For this, the following indicators are proposed:

Run time multiplier (RTM): This indicator (Ossa et al. [15]), provides an adjustment factor in order to compensate lack of distribution uniformity.

RTM is related to the lower-half distribution uniformity $\left(\mathrm{DU}_{\mathrm{LH}}\right)$ in the following way:

$$
R T M(-)=\frac{100}{D U_{L H}} \text { where } D U_{L H}(\%)=38.6+(0.614 \times D U)
$$

Real irrigation system efficiency $\left(E_{r s}\right)$ : In this work, this indicator is adapted from [15] with the aim of comparing the irrigation water that is beneficially used for plant grown and the real water supplied in the plot. Here is proposed to calculate $\mathrm{E}_{\mathrm{rs}}$ for a high water requirements period (test week) with the target to compare the real applied volume with the theoretical needed by plants. Another complementary indicator is defined, $\Delta \mathrm{r}$, to value variations from $\mathrm{NR}_{\mathrm{nw}}$.

$$
\begin{gathered}
E_{r s}(\%)=100 \times\left(\frac{N R_{n w}}{N R_{a p l i}}\right) \text { where } N R_{a p l i}=t_{w}\left(\mathrm{x}_{\mathrm{m} / t_{c c}}\right) \\
\Delta r(\%)=\frac{100 \times N R_{a p l i}}{N R_{n w}}
\end{gathered}
$$

where $\mathrm{NR}_{\mathrm{nw}}$ is the net water requirement in the test week (mm), $\mathrm{NR}_{\text {apli }}$ is the net water applied in the test week $(\mathrm{mm}), \mathrm{t}_{\mathrm{w}}$ is the irrigation time in the test week ( $\left.\mathrm{min}\right)$ and $t_{c c}$ is the irrigation time for each catch-can test (min).

To sum up this first part of the assessment, it is essential to highlight that the main purpose is to quantify the ratio between applied water and irrigation requirements and how the water distribution is. In this work are recommended some indicators but these coefficients could be changed by others because the most important is the goal and not the tools.

\subsection{Energy efficiency characterization}

In urban landscape irritation systems water is supplied by means of pressurized networks that carry important energy consumptions. Therefore, another important issue of the assessment is quantifying the pumping energy. For this, some indicators should be used to assess performance system. In this study, the proposed indicators are adapted from the official indicators of IDAE [16] and Abadía et al. 
[17], and they are very common in auditing process from agriculture irrigation networks. Three coefficients are defined:

General energy efficiency (EEG): This coefficient assesses the global efficiency of the irrigation network including the pump unit. EEG is given by

$$
E E G=E E B \times E S E
$$

Pumping energy efficiency (EEB): This first factor represents the balance between the supplied energy by pumps $\left(\mathrm{E}_{\mathrm{su}}\right)$ and the absorbed energy $\left(\mathrm{E}_{\mathrm{abs}}\right)$. EEB is given by

$$
E E B(\%)=\frac{E_{s u}}{E_{a b s}} \times 100
$$

Both factors can be obtained by means of direct measurements in the system during a representative period of time. In particular, $\mathrm{E}_{\mathrm{su}}$ for each period in which different intakes work simultaneously (shift) into the operating time is given by the following equation:

$$
E_{s u}(k W h)=3.6 \sum_{i=1}^{n} \gamma Q_{i} H_{i} t_{i}
$$

where $\gamma$ is the specific weigh of water $\left(9800 \mathrm{~N} / \mathrm{m}^{3}\right), \mathrm{Q}_{\mathrm{i}}$ is the flow measured with a flow meter $\left(\mathrm{m}^{3} / \mathrm{s}\right), \mathrm{H}_{\mathrm{i}}$ is the pressure measured with a pressure sensor $(\mathrm{m})$ and $\mathrm{t}_{\mathrm{i}}$ is the shift time (s).

The other component of EEB is $\mathrm{E}_{\mathrm{abs}}$. In this case, for each shift, the factor should be obtained measuring with a network analyzer. $E_{\text {abs }}$ is defined as follows, including an energy value that considers a global efficiency of the pump. The equivalent equation is given by

$$
E_{a b s}(k W h)=3.6 \sum_{i=1}^{n} \frac{\gamma Q_{i} H_{i} t_{i}}{\eta_{b_{i}} \eta_{m e_{i}} \eta_{v a r_{i}}}
$$

where $\eta_{\mathrm{b}}$ is the global efficiency of the pump, $\eta_{\mathrm{me}}$ is the electric motor efficiency and $\eta_{\text {vdf }}$ is the variable frequency drive efficiency.

Energetic supply efficiency (ESE): This indicator represents the ratio between required supply energy at the system and real energy provided by the pumping. It is given by:

$$
\operatorname{ESE}(\%)=\frac{|\Delta E|}{I C E} \times 100
$$

where $\Delta E$ is the energy balance of supply (m) and ICE is rate of energy charge (m) and if there is an only pumping source, this indicator is equivalent at head supplied by the pump, i.e., is the specific supplied energy by pumps ( $\left.E_{\text {su }}\right)$.

Particularly, $\Delta \mathrm{E}$ quantifies the energy needed to satisfy, for each shift of the sequence, the head required by the most pressure demanding intake $\left(\mathrm{H}_{\min }\right)$. The system works with an average head which is defined by the garden managers, in such a way, that irrigation requirements and uniformity irrigation are upper than a minimum recommended. The equation is the following, where $V_{j}$ is the demander volume water for each shift and $\mathrm{V}_{\mathrm{T}}$ is the total irrigation volume. 


$$
|\Delta E|=\frac{\sum_{i=1}^{n} V_{j}\left(\operatorname{Hin}_{j}\right)}{V_{T}}
$$

The main objective of this last part of the assessment is analyze energy efficiency systems but other indicators and tools, like direct measurements in the pumping unit, could be used. This methodology could be considered a first approximation in the state of the system.

\section{Results and discussion}

\subsection{Water needs for urban landscapes}

In the UPV gardens, water needs were calculated following the proposed protocol and considering the weather conditions during 2013 obtained in an automated meteorological station located in the UPV campus. Results per hydrozones, compared with real water consumptions, are shown in the Table 2.

Table 2: Water needs for each scenario.

\begin{tabular}{|c|c|c|c|c|}
\hline \multirow{2}{*}{ Hydrozones } & Area & Percentage & $\mathrm{NR}_{\mathrm{n}}$ & $\mathrm{NR}_{\mathrm{r}}$ \\
\hline & $\mathrm{m}^{2}$ & $\%$ & $\mathrm{~mm} /$ year & $\mathrm{mm} /$ year \\
\hline 1 & 45,168 & 41.7 & 71 & 84 \\
\hline 2 & 21,771 & 20.1 & 429 & 568 \\
\hline 3 & 17,442 & 16.1 & 286 & 378 \\
\hline 4 & 20,997 & 19.4 & 43 & 50 \\
\hline 6 & 2,871 & 2.7 & 286 & 378 \\
\hline \multicolumn{4}{|c|}{ *Methodology consumption (mm/year) } & Max: 568 \\
\hline \multicolumn{4}{|c|}{ Real consumption (mm/year) } & 998 \\
\hline
\end{tabular}

*In the case study, the scenario called 5 does not exist.

The above results show the importance of adjusting irrigation dose to the strict requirements of the species planted depending on the microclimate in which they are installed. Water needs calculated using the methodology reaches a minimum saving of $43 \%$ if plots are irrigated with the volume from those more demanding. In another hypothetical scenario where water needs were weighted based on the representation of each hydrozone in the garden, the maximum saving could reach $77 \%$ consuming a total amount of $230 \mathrm{~mm} /$ year.

\subsection{Uniformity irrigation measurements}

Uniformity irrigation assessment was carried out in four plots of the UPV garden. Interpolated rainfall results $(\mathrm{mm} / \mathrm{min})$ are shown in the fig. 2 . There are areas with high rainfall and others with an important deficit of water coverage. Usually these scarcity problems match up with emitters damaged. 

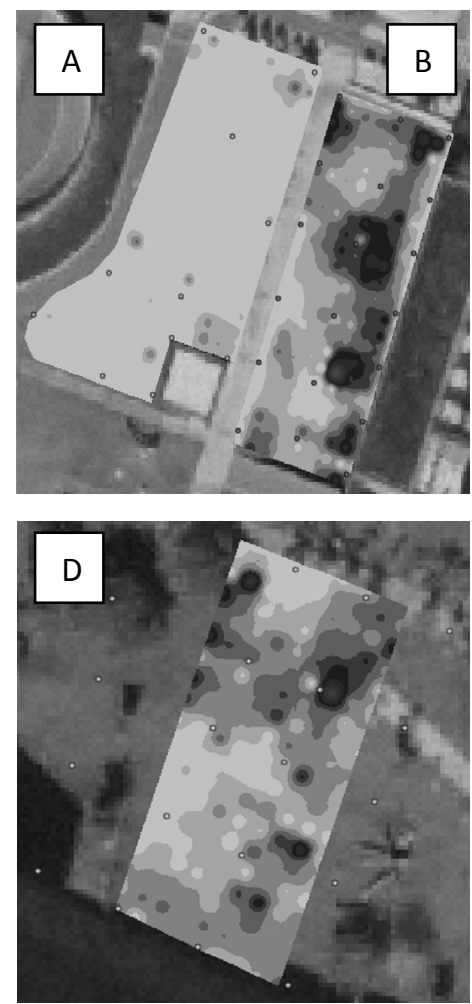

$00,00000.0 .106$

$0,106 \cdot 0,158$ $0.158 \cdot 0.211$ $0.211 \cdot 0.264$

$0,264-0,322$

$0,322-0,390$

$0,390 \cdot 0.517$

$0,516 \cdot 0.733$

$0,793-1,012$

$1,012 \cdot 1,344$
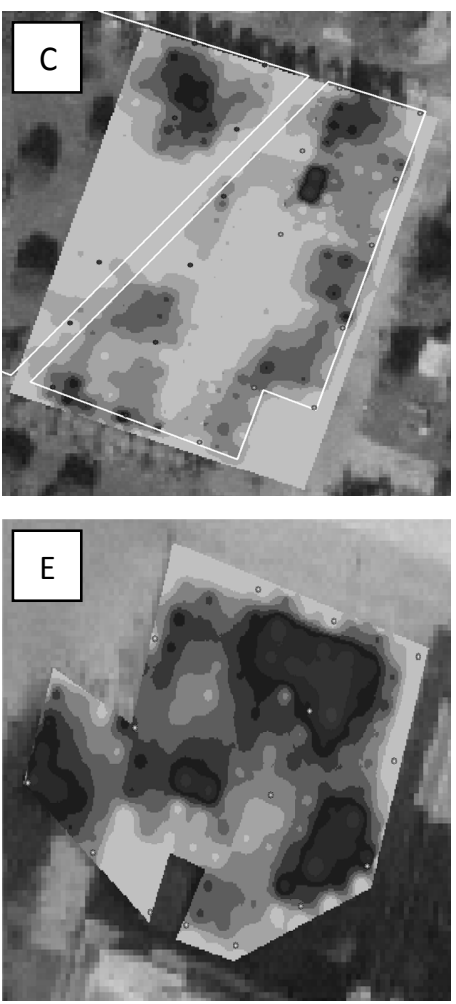

Figure 2: Interpolated rainfall $(\mathrm{mm} / \mathrm{min})$ registered in the UPV gardens.

Another problem detected is the presence of several flooded areas that even reach the outer limits of the garden. The main cause was vegetation and urban furniture interception with the water distributed by sprinklers. Besides, in sloped plots this effect generates water losses by run-off. It becomes clear that there are uniformity irrigation problems in every plot which must be solved to improve irrigation efficiency.

The assessment methodology was completed with the uniformity and efficiency indicators calculation. The reference values could be consulted in Ossa et al. [15] and Keller and Bliesner [18]. Results are showed in the Table 3.

These results show a deficient distribution, both DU and CU (except DU in the plot C) are under the recommended range. This irregularity was confirmed by means of the above assessment of interpolated rainfall. The indicator SC evinces that irrigation should be increased in every plot, and especially in the plot $\mathrm{E}$ about $65 \%$ to satisfy the less irrigated areas. The rise would mean overwatering other areas, so it is recommended to solve distribution and density emitters before increasing irrigation rates. 
Table 3: Results of DU, CU, SC, RTM, $\mathrm{E}_{\mathrm{rs}}$ and $\Delta \mathrm{r}$ for the studied plots.

\begin{tabular}{|c|c|c|c|c|c|c|c|c|c|c|}
\hline \multirow{2}{*}{ Plot } & Hydrozone & Area & \multirow{7}{*}{ 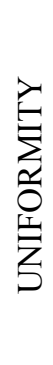 } & $\mathrm{DU}$ & $\mathrm{CU}$ & $\mathrm{SC}$ & \multirow{7}{*}{ 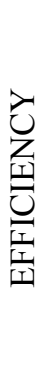 } & RTM & $\mathrm{E}_{\mathrm{rs}}$ & $\Delta \mathrm{r}$ \\
\hline & - & $\mathrm{m}^{2}$ & & $\%$ & $\%$ & $\%$ & & - & $\%$ & $\%$ \\
\hline A & 9 & 1092 & & 39 & 33 & 13 & & 1.60 & 207 & -48 \\
\hline B & 9 & 1724 & & 56 & 45 & 65 & & 1.37 & 57 & +175 \\
\hline $\mathrm{C}$ & 8 & 1897 & & 62 & 31 & 8 & & 1.30 & 130 & -77 \\
\hline D & 8 & 1797 & & 57 & 56 & 21 & & 1.36 & 92 & +109 \\
\hline $\mathrm{E}$ & 9 & 809 & & 56 & 37 & 65 & & 1.38 & 51 & +196 \\
\hline
\end{tabular}

Regarding to efficiency indicators, RTM in average could be considered acceptable in the majority of plots apart from the A. These results involves that the compensation time for increase irrigation uniformity is necessary but it is not excessive. Finally, in every assess plot, $\mathrm{E}_{\mathrm{rs}}$ is outside of recommended range. The indicator $\Delta \mathrm{r}$ shows plots under and over irrigated compared with $\mathrm{NR}_{\mathrm{nw}}$. In conclusion, the irrigation is not uniform and therefore, being inefficient in the case study.

\subsection{Energy efficiency characterization}

Two consecutive days in a high necessity period have been studied. During these days, flow, pressure and power were registered. The unitary energy consumption obtained was $0.59 \mathrm{kWh} / \mathrm{m}^{3}$. In addition, adapted indicators from IDAE were used to assess the efficiency system. For the $5^{\text {th }}$ of June the EEB was $47.9 \%$ and the EEG was $23.9 \%$. For the $6^{\text {th }}$ of June the EEB was $42.6 \%$ and the EEG was $21.0 \%$. The limit value considered acceptable for EEB is $45.0 \%$ and for EEG is $25 \%$, IDAE [16]. Thus, EEB and EEG in both days are not acceptable. Therefore results show that the system is not operated properly under current conditions.

\section{Conclusions}

This work presents a methodology for assessing urban landscapes from the agronomic, hydraulic and energetic point of view. First, a group of recommendations base on the landscape coefficient method is suggested to calculate irrigation needs in several hydrozones. Results for w2 landscaped area in the UPV gardens showed a potential saving of $43 \%$ in terms of water. Then a serial of uniformity and efficiency irrigation indicators has been applied to evaluate irrigation quality. The assessment picks up damaged emitters and wrong spacing patterns. Finally, some energy performance indicators have been applied to assess the network operation. These results showed that EEG was not acceptable. To solve this problem, future works will be aimed on improving energy efficiency by optimizing irrigation scheduling. 


\section{Acknowledgements}

This work was supported by the SP20120823 grant from Programa de Apoyo a la Investigación y Desarrollo (PAID-06-12) of the Vicerectorado de Investigación de la Universitat Politècnica de València; and co-funded by the European Commission under the 7th Framework Programme (FP7) for Research and Technological Development (311903) in the project "Flexible and Precision Irrigation Platform to Improve Farm Scale Water Productivity".

\section{References}

[1] Instituto Nacional de Estadística. http://www.ine.es

[2] Soto-García, M., Martín-Gorriz, B., García-Bastida, P.A., Alcon, F. \& Martínez-Álvarez, V. Energy consumption for crop irrigation in a semiarid climate (south-eastern Spain). Energy 55, pp. 1084-1093. 2013.

[3] Burés, S. Avances en xerojardinería. Ediciones Horticultura, S.L. Consejería de Agricultura y Pesca. Junta de Andalucía. 2000.

[4] Costello, L.R., Jones, K.S., Matheny, N.P., \& Clark, J.R. A guide to estimating irrigation water needs of landscape plantings in California. The landscape coefficient method \& WUCOLS III. University of California Cooperative Extension, California Department of Water Resources, U.S. Bureau of Reclamation California. 2000.

[5] Allen, R. G., Pereira, L. S., Raes, D., and Smith, M. Crop evapotranspiration; Guidelines for computing crop water requirements. FAO lrrigation and Drainage Paper No. 56. United Nations. Roma. 1998.

[6] Van Dam, J.C., Huygen, J., Wesseling, J.G., Feddes, R.A., Kabat, P., Van Walsum, P.E.V., Groenendijk, P. and Van Diepen, C.A. Theory of SWAP version 2.0. Simulation of water flow, solute transport and plant growth in the Soil-Water-Atmosphere-Plant environment. Wageningen University and Alterra. Technical Document, 45. 1997.

[7] Qualls, R.J., Scott, J.M., De Oreo, W.B. Soil moisture sensors for urban landscape irrigation. Effectiveness and reliability. Journal of the American Water Resources Association. 37(3) pp. 547-559. 2001.

[8] Contreras, F. Clasificación de especies de Jardín según sus necesidades hídricas para la Región de Murcia. Instituto Murciano de Investigación y Desarrollo Agrario y Alimentario. 2006.

[9] Burt, C. M., Clemmens, A. J. \& Strelkoff, K. H. Irrigation performance measures: Efficiency and uniformity. Journal of Irrigation and Drainage Engineering, 123(6), pp. 423-442. 1997.

[10] Micker, J. Mobile irrigation laboratory urban irrigation evaluation training manual, USDA, Natural Resources Conservation Service, Gainesville, Fla. 1996.

[11] American Society of Agricultural Engineers (ASAE). Testing procedures for determining uniformity of water distribution of center pivot and lateral move irrigation machines equipped with spray or sprinkler nozzles. ASCES436.1. 48th Ed., St. Joseph, Mich. 2000. 
[12] ArcGIS 10.1. http://resources.arcgis.com/en/home/

[13] Christiansen, J. E. Irrigation by sprinkling. Univ. Calif. Agr. Exp. Sta. Bull. 670. 1942

[14] Merriam, J.L. \& Keller, J. Farm irrigation system evaluation: a guide for management. CEE Department, Utah State University, Logan. 1978.

[15] Ossa, J., McCabe, J., Allen, R., Carleton, B., Carruthers, B., Corcos, C., Howell, T.A. \& Spofford, T.L. Landscape Irrigation Scheduling and Water Management. WMC of the Irrigation Association. 2005.

[16] IDAE. Ahorro y eficiencia energética en agricultura de regadío. Instituto para la Diversificación y el Ahorro de la Energía. ISBN: 84-86850-94-0. Madrid. 2005.

[17] Abadía, R., Rocamora, C., Ruiz, A. \& Puerto, H. Energy efficiency in irrigation distribution networks I: Theory. Journal of Agricultural Biosystems Engineering. Elsevier, 101, pp. 21-27. 2008.

[18] Keller, J. and Bliesner, R.D. Sprinkle and trickle irrigation. New York, Van Nostrand Reinhold. 1990. 